\title{
UNIVERSITY AVIATION EDUCATION: AN INTEGRATED MODEL
}

\author{
Merrill R. Karp \\ Arizona State University East
}

\begin{abstract}
As indicated at the Regional Air Transport Training Convention and Tradeshow (RATS 2000) at Daytona Beach, FL, on February 8-9, 2000, the United States regional airlines fully recognize that the frequently-discussed shortage of regional airline pilots is now a fact rather than a forecast. The regional airline conference attendees also felt that potential pilot shortages in the major airlines are probably not far behind. Over the past few decades, the airline industry has relied upon the military for its primary source of experienced pilots. However, with increased commercial airline expansion, coupled with the Vietnam era trained pilots approaching retirement age and the recent low military pilot training production, the United States now faces a shortage of highly experienced pilots in both the military and the commercial airline industry. While flight programs have been developed to meet these shortfalls with increased training, consideration should also be given to improving the aviation education process itself, which is the foundation of flight training. University aviation training programs, because of their comprehensive academic environments, offer excellent opportunities to develop and deliver state-of-the-art aviation curricula and become the new primary resource for commercial airline pilots. A key question to help resolve the impact of the commercial pilot shortage should be: Can an enhanced aviation academic education and flight training program help accelerate university-trained pilots into airline cockpits. This paper draws upon research conducted in the Aeronautical Management Technology Department at Arizona State University (Karp, 1996) and addresses potential educational enhancements through the implementation of an integrated aviation learning model, the Aviation Education Reinforcement Option (AERO). The AERO model is a learning strategy that incorporates elements of the adult education paradigm, learning style theory, cooperative and collaborative learning techniques, and personal computer-based aviation training devices (PCATDs), to span the long-term retention and application gap that can occur between the classroom and the flight line. This paper suggests that the AERO model, when combined with flight training that emphasizes airline procedures from the very beginning, has the potential to reduce the pilot training time required between the universities' academic classrooms and flight training environments, and the commercial airline cockpit.
\end{abstract}

\section{BACKGROUND}

A United States Department of Transportation Federal Advisory Committee study in 1993, directed by Congress, projected a shortage of qualified airline pilots which could impact the future availability of 
commercial air transportation in the United States. This study indicated that expansion of airline capacity, in combination with retirements from the airline pilot force and a reduced pool of former military pilots, would result in a national shortage of qualified pilots through 2010 unless positive actions were taken. Shortages in the major airlines, and the decreased resource of military trained pilots, has, in fact, created an increased flow-through demand on the regional airlines for pilots, further impacting the regional airlines' training loads and experience levels.

A pertinent commercial pilot supply issue to consider is that of the depth and quality of the aviation academic education, as well as the flight training, of those future airline pilots. Because of the increasing sophistication of modern aircraft and high technology equipment, this issue underscores a need to examine, and restructure where necessary, the training options for potential airline pilots. This action is required to ensure that the aviation education process is an in-depth, effective transfer of knowledge across a broad spectrum of aviation academic subjects. When considering aviation education, the academic component of the flight training plays a critical role in providing the knowledge base for a new pilot. This academic education has the potential to build an exceptionally solid foundation for ensuring the high standard of technical and flying knowledge needed for future airline pilots.

One factor affecting the available commercial pilot pool is the length of time it takes an aviation flight school graduate to attain the number of flying hours to apply for employment in the airlines. The typical "flight-time building path" for a new pilot involves flying first as an instructor pilot and then as regional pilot; this path could take 6 to 8 years to build the required flight time prior to being eligible to apply to the major airlines. This historical emphasis on flight hours as an airline pilot selection criterion may be efficient when there is an adequate source of commercial pilots; however, an alternative approach that should be considered, in light of the current pilot shortages, is that of a proficiency-based flight training program. This is similar to what the U.S. military and a number of foreign air carriers, such as Lufthansa German Airlines, employ (Karp, 1996).

However, in spite of forecasted commercial pilot shortages and the rapid increase in the sophistication of modern aircraft and the complexity of the flight and navigation environment, the aviation education process itself has changed very little over the years to meet the challenges of proficiency-based flight training. This situation suggests the need to revisit the current aviation education process and develop a new aviation learning model which helps accelerate pilots, who have the required long-term knowledge retention and airline focused flight training, into regional airline cockpits.

\section{ACADEMIC UNDERPINNINGS}

Prior to suggesting an aviation learning model to enhance the knowledge transfer retention and increase knowledge application from the classroom to the flight line, it is important to consider the academic underpinnings that could be used in the development of such an aviation learning model.

\section{Adult Learning}

While the term "adult learner" is often thought to only include persons seventeen or older who are not enrolled fulltime in high school or college, the term adult learner in its broadest sense applies to every adult participating in organized education 
(Cross, 1979). While entry-level university students are technically "adult learners," those new university students' educational background most likely was not under the adult learning model, but rather under the adolescent learning model. In this case, university educators must move the students into the adult, or self-directed learning, model as soon as possible.

\section{Adult Motivation}

An important area to take into consideration in planning adult education programs is the learners' motives. The most important perspective in adult learning motivation is that adults are voluntary, practical learners who pursue education for its use to them. If education is to serve this voluntary learning force, then educators need to understand what to do to motivate their particular learners (Knowles, 1980). Studies indicate that adult learners appear to be very responsive and motivated to action-oriented learning, that is, learning while doing (Cross, 1979). Adults who are motivated, and see a need to learn something new, are quite resourceful -- and successful. The key to using adults' natural motivation to learn is tapping into their most teachable moments: those moments in their lives when they believe that they need to learn something different. The idea of this window of opportunity for learning applies not only to peoples' motivation to learn, but also to their ability to retain what they do learn. In contrast, if the learners acquire a new skill or knowledge, but then have no opportunity to use it or are delayed in using it, the skill or knowledge will fade (Zemke \& Zemke, 1995).

\section{Adult Education Facilitation}

Noted adult educator Stephen
Brookfield (1989) maintains that there are six principles of adult education facilitation which should be considered: First, adults voluntarily participate in the educational activity, and as such, the decision to learn is the learners' -- they cannot be forced to learn. Second, there must be a mutual respect between the learner and the educator. Third, there must be a collaborative spirit in determining the course objectives, learning methods, and the evaluative process. Fourth, there must be a continuous process of investigation and exploration of the subject matter. Fifth, time must be allotted for critical reflection. And sixth, the education must be self-directed by the learners, with the facilitator assisting the adults to reach their educational goals.

Although much of adult learning is self-directed, the classroom learning environment is still the critical link. Lecture alone is effective and essential when the learners have little or no knowledge of the subject matter. However, facilitation is more effective than lecture when the goal is to engage learners in setting objectives, to tap into their prior experience and knowledge, or to help the participants reach a consensus. Breaking participants into small learning groups to exercise new skills and knowledge in relative safety is critical to understanding and retention. Participants in an adult learning process are normally hesitant to try out new knowledge and skills in front of others. Small "praxis" teams that practice and reflect can overcome the reluctance to risk (Zemke \& Zemke, 1995).

\section{Cooperative and Collaborative Learning}

In parallel with praxis teams and adult education, cooperative and collaborative learning techniques appear to be particularly applicable for aviation students. In cooperative learning, the students participate in small, structured group activities as they work together to 
solve problems assigned by the educator. By contrast, in collaborative learning the students are asked to organize their joint efforts and negotiate, among them, who will perform which task. The instructor does not always actively monitor the groups and refers all substantive questions back to them for resolution (Bruffee, 1995; Matthew, Cooper, Davidson, \& Hawkes, 1995).

\section{Computer-Based Training}

With the increased access to computer-based tutoring programs, students are moving away from passive reception of information to more active engagement in the acquisition of knowledge (Kozma \& Johnston, 1991). Computer programs for tutoring technical subjects can be particularly useful in aviation education. ComputerBased Training (CBT) programs can be used extensively for pre-class preparation, as well as post-class review and reinforcement. CBT programs allow the student to accomplish self-paced learning in a non-threatening environment. In addition to supporting the CBT programs, the same basic computer equipment for aviation education can be augmented with a control yoke and throttles to be used with personal computer-based aviation training devices (PCATDs) with flight simulator programs. These personal computer-based flight simulator programs are relatively low-cost training vehicles that can be easily and effectively integrated into an aviation education curriculum. They are well suited as an educational bridge between the basic, traditional aviation classroom and the advanced, high technology aviation flight environment (Karp, 1996).

\section{Learning Style Theory}

Learning style theory, that is, the way people learn best, is of considerable importance in developing and delivering aviation academic programs. One model suggests that there are three recognized primary, or dominant, learning styles: First, visual learners, who learn best by reading or looking at pictures. Second, auditory learners, who learn best by listening. And third, hands-on, tactile, or kinesthetic learners, who need to use their hands or whole body to learn (Filipczak, 1995). If knowledge transfer is to take place within the entire classroom population, all of these dominant learning styles should be addressed in the academic environment.

Gender also plays a role in learning style differences between students in the classroom, in a laboratory, or on a flight line. Research has shown that women learn in many different ways than men (Turney, 1995). For example, while men often prefer debate-like situations in which they pursue knowledge, women most frequently like to share and learn by interacting with each other (Tannen, 1990). Additionally, Females often are very participatory in their learning styles, while men tend to be more independent (Emanuel \& Potter, 1992). Aviation curriculum development and delivery should take into consideration those learning styles that are both unique as well as common to men and women in order to maximize their retention, and their success, in the aviation career field.

In developing educational programs, it is important for the instructor to understand how his or her students learn the best and why they succeed. Because of the depth and complexity of the subject matter, aviation academic instructors must present the course material in ways that satisfy the different needs and styles of the aviation learners. Likewise, each student must understand his or her dominant learning style and maintain more focused attention to the information when it is being presented in a teaching style 
which is not easily compatible with their learning style.

\section{Learning Style Research}

To examine a representative sample of pilots' dominant learning styles (visual, auditory, or hands-on), qualitative research interviews were conducted with 117 pilots (ranging from private pilots to $\mathrm{F}-16$ pilots) to identify the respondents' dominant learning styles, as well as to explore potential enhancements and restructuring to aviation academic programs (Karp, Turney, \& McCurry, 1999; Karp, Condit, \& Nullmeyer, 1999). The learning style assessment of the 117 pilots revealed that over 44\% were hands-on learners, and almost $60 \%$ were either hands-on, or hands-on/visual learners (Table 1). In contrast to the majority of the pilots being predominantly hands-on or hands-on/visual learners, the research indicated that most classroom instruction environments were auditory in nature, with visual supplementation, and very little, if any, hands-on learning.

\begin{tabular}{|l|c|c|}
\hline \multicolumn{1}{|c|}{ Learning Style } & $\underline{\text { Number }}$ & $\underline{\text { Percentage }}$ \\
\hline Visual & 38 & $32.5 \%$ \\
\hline Auditory & 8 & $6.8 \%$ \\
\hline Hands-on & 52 & $44.4 \%$ \\
\hline Hands-on/Visual & 16 & $13.7 \%$ \\
\hline Visual/Auditory & 3 & $2.6 \%$ \\
\hline
\end{tabular}

Table 1. Dominant learning styles $(n=117)$.

\section{Screening and Selection for Training}

Screening individuals prior to
entering training could also play an
important factor in selecting potentially
successful candidates for training programs
that require a high capital investment. The

selective screening of individuals has always been a major factor used by the military, which places pilots with limited flying hours in demanding flying positions. One of the reasons that former military pilots have historically occupied a high percentage of the airline cockpits is because the military has maintained high pilot selection and training standards. Almost all military aviators have a 4-year college degree. Additionally, applicants have to be screened to meet related physical and psychological requirements. The pilot selection and testing process is considered a key to the success of military pilot training and includes tests for general cognitive abilities, personality, psychomotor skills, and physical fitness to eliminate individuals who are less likely to succeed (Karp, 1996).

Lufthansa Airlines has been using comprehensive screening programs since the 1950s with tremendous success. Their screening programs have resulted in an exceptionally high pilot training completion rate of more than $90 \%$ (Dr. Karsten Severin, Director of Psychology, Lufthansa German Pilots School, personal interview, Bremen, Germany, March 3, 1995). The German Aerospace Research Institute (DLR) has been responsible for the screening of pilots for Lufthansa Airlines for over 40 years. This screening has resulted in selection criteria such that less than $10 \%$ of the applicants who pass the screening fail to complete the flight training. In addition to the physical examinations for entry into pilot training, the DLR screens for knowledge, ability, and personality. "Knowledge" test areas include school grades, English language, mechanical and technical subjects, and numeral facility. "Ability" testing looks at numerical reasoning, memory (auditory and visual), perception and attention, psychomotor coordination, and multiple task capacity. "Personality" screening, on which Lufthansa places a high importance, explores 
achievement motivation, rigidity, mobility, risk taking, vitality under stress, extroversion, emotional stability, and stress resistance. The DLR contends that if the total profile of knowledge, ability, and personality is at or above their normative group in all areas, the individual has an extremely high probability of being a successful airline pilot (Dr. Klaus-Martin Goeters, Director, Aviation and Space Psychology Department, German Aerospace Research Institute, personal interview, Hamburg, Germany, April 2, 1996).

\section{THE INTEGRATED AVIATION LEARNING MODEL}

Considering the academic underpinnings, an initial integrated aviation learning model, the Aviation Education Reinforcement Option or AERO modelC was developed to increase long-term knowledge retention and enhance application of aviation education (Karp, 1996). This AERO model (Figure 1) has been instituted at Arizona State University and was recently further refined to key on accelerating university aviation-trained pilots into the regional airlines (Karp, McCurry, \& Harms, 2000).

\section{Integrated Learning Model Components}

Inputs. While pilot candidates in a first officer training program can have varying levels of experience, university-age individuals, with little or no flying experience, make excellent candidates because they have minimal "bad flying habits" or misconceptions.

Pre-Training Screening Program. A key element of a first officer training program should be to test and screen candidates for physical condition, and psychomotor, personality, and cognitive skills, to help identify those who have the potential for succeeding in flight training and fitting the "airline model."

\section{Integrated Aviation Classroom.}

Since university-age students are in a transition from adolescent learning to adult learning, beginning aviation students must be "focused" toward self-directed learning to attain their maximum potential. This includes motivating the learners by stressing the need to acquire the knowledge and to recognize that this is the time to learn it. While a lecture alone is effective when learner has little or no knowledge of subject, it is important to recognize that facilitating the knowledge transfer is a more effective format to increase knowledge by engaging learners in an exchange of ideas in problemcentered discussions and tapping into their prior experiences.

Adult Education Principles. In line with the adult education model, goals for learning objectives and the methods for knowledge transfer and evaluation are important details for the educator to explain, in order to assure a "buy-in" by the learners to the "what" and "when" of the aviation learning process. Additionally, in adultfocused aviation education, the extensive amount of technical material that must be covered for the course and the limited time available in the classroom, requires that almost every moment of class time be used to expand on, or to integrate, the foundational knowledge. This requires extensive preparation by the students prior to each class or laboratory. Since adults cannot be "forced" to learn, it is important to emphasize that the students, themselves, must make that decision, and then help "selfdirect" the process. 
In-depth Theory. In order for pilots to apply recently acquired knowledge to new situations, they must have an in-depth understanding of systems and procedures. That is, a detailed comprehension of the why, and not just the what. Lecture on foundational information should be delivered in the classroom using a video projector to display computer presentation programs and personal computer-based flight simulator programs, to reinforce the lessons.

Immediate Application. Application of acquired knowledge immediately after the classroom experience is critical for adult learning and reinforcement to take place. Following each classroom lesson (for example, magnetic compass operations), learners should go to a laboratory for immediate application of the lesson components (for example, magnetic dip-error lead-points) to reinforce the knowledge transfer by flying specific lessons in PCATDs, flight training devices (FTDs), or flight simulators. PCATDs can provide this immediate application at a low cost and are very flexible for different curricula. Additionally, the immediate application in the PCATDs helps provide the educational components in multiple learning styles, thereby meeting more individuals' learning needs (hands-on, tactile; visual; and auditory learning) than are provided by classroom lecture alone. It is important to note that this paper stresses the use of PCATDs as a component of the academic classroom, and not necessarily as a component of the flight training program. 

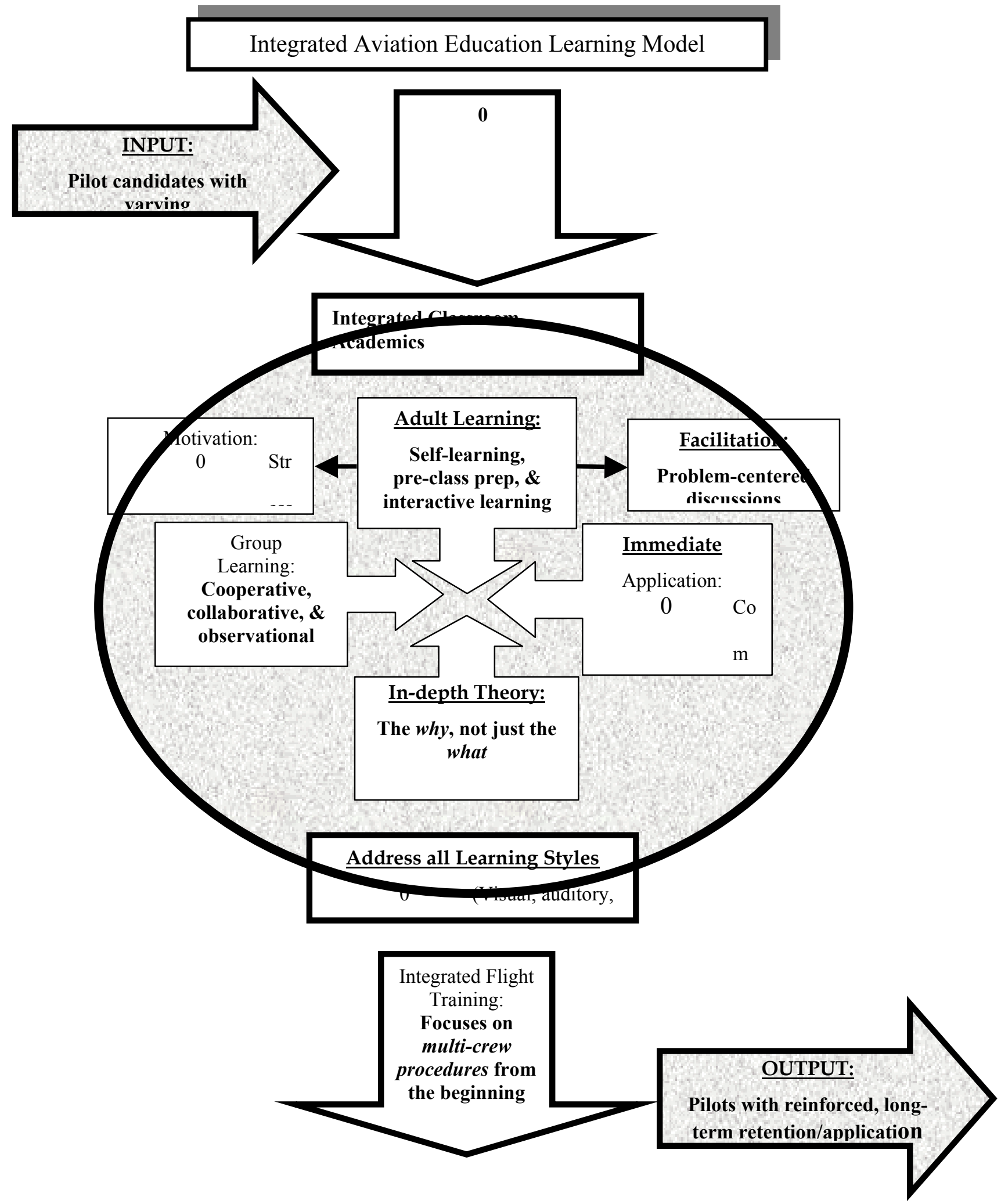

Figure 1. Integrated Aviation Learning Model: Aviation Education Reinforcement Option (AERO Model) $)_{\odot}$ 
Group Learning. Group learning in small "praxis teams" is particularly applicable for aviation students. Group learning includes cooperative, collaborative, and observational learning. Cooperative learning takes place when the learner teams give presentations and fly simulator missions as assigned by the educator. In contrast, collaborative learning takes place when the educator makes an overall assignment to the group for presentations or flight simulator missions, and the group itself determines who will do what, and how. In the collaborative learning laboratory, the teams "fly" approaches or Line-Oriented Flight Training (LOFT) profiles on the PCATD, using "pilot-flying / pilot-not-flying" procedures early in their training to reinforce multi-crew concepts, as well as the airline oriented challenge-and-response type checklists and procedures. Collaborative learning has proven to be an especially reinforcing process for aviators. The observational learning element in group learning includes a non-flying team observing the team that is flying in the collaborative flight simulator laboratory. The observational team then provides a post-flight assessment. This group learning component provides direct peer feedback for the team who is flying, and objective observational learning for the non-flying team.

Learning Style Theory. Throughout the various stages of aviation learning (for example, educator lecture, learner cooperative and collaborative PCATD flight simulator missions), the material should be delivered in visual, auditory, and hands-on learning styles to address all students' dominant learning styles. Learning style theory is a major component of the AERO model.

\section{Integrated Flight Training. Integrated flight training focuses on multi-crew procedures from almost the beginning of flight training. While initial pilot training may have to be single-pilot oriented, moving quickly to}

airline-type procedures and checklists should help pilots minimize "procedure" transition issues when going to the airlines.

Output. The goal of this aviation learning model is to produce a pilot who has long-term retention of the knowledge, and can successfully apply that knowledge to new situations without having previously encountered the new situation.

\section{RECOMMENDATIONS}

1. Aviation education and training institutions should adopt an integrated aviation learning model, such as the AERO Model in Figure 1 , which uses the adult education paradigm and cooperative and collaborative learning techniques, in concert with PCATD flight simulator programs for immediate classroom hands-on application of airline multi-crew cockpit procedures.

2. The U.S. airlines should recognize proficiency-based training, in addition to experience-based training, in their criteria for pilot employment application eligibility. With the projections of shortages of qualified, commercial airline pilots in the U.S. airline industry, the timing is favorable now to make a bold change in employment criteria. This major change need not be addressed by individual regional and major airlines alone, but rather should be considered by a coalition of the airline industry, universities with aviation programs, and the federal government.

3. Create an aviation industry, university, and government aviation education and training coalition. This joint coalition would, in an on-going forum, define commercial pilot needs, develop training standards, furnish aviation education and training concepts to provide the industry with the best trained 
and the safest pilots in the world.

4. Develop a standard screening program that predicts an individual's potential for success as an airline pilot and assists interested applicants with their decisions on whether or not to pursue careers as airline pilots, prior to making the required capital investment for the training.

5. Establish relationships between university and regional airlines for participation in the pre-training selection process, training program development, internships, and early identification for employment.

\section{CONCLUSIONS}

As aviation technology and the international airspace structure become more complex, aviators must acquire, on a high retention and application level, a large amount of information. An integrated learning model applied to modern aviation education should improve understanding, efficiency, effectiveness, and safety in aviation education and training programs. The incorporation of an integrated aviation learning model would also potentially help ease the projected shortage in the commercial airlines by substituting indepth, long-term knowledge retention and proficiency for some of the airlines' current flying hour hiring requirements. Affiliations between major airlines, regional airlines, and universities must be established to bridge the gap in the current training and experience pipeline from the university classroom to the regional airlines' cockpits.

The recruitment and retention of women in aviation programs are additional factors to consider in meeting future commercial pilot requirements. The full utilization of female resources, as well as male resources, is important. Women constitute only a small percentage of the commercial pilot force, yet they comprise a very large resource pool from which the commercial aviation industry can draw. In order to attract and retain the best people in aviation academic programs, aviation academic providers must design their curriculum and delivery vehicles to meet their students' specific learning styles, whether they are male or female.

The investment in time for curriculum development in a structured, integrated aviation education model such as the AERO model should pay high dividends in expanding the learners' knowledge base, enhancing their flexibility to address new situations, increasing their productivity and effectiveness, and accelerating pilot production into the airlines. 


\section{REFERENCES}

Brookfield, S. (1989). Facilitating adult learning. In Merriam and Cunningham (Eds.), Handbook of adult and continuing education. San Francisco: Jossey-Bass.

Bruffee, K. (1995, January/February). Sharing our toys: Cooperative learning versus collaborative learning. Change, 27, 12-18.

Cross, K. (1979). Adult learners: Characteristics, needs, and interests. In Peterson, R. and associates (Eds.), Life learning in America. San Francisco: Jossey-Bass.

Emanuel, R. \& Potter, W. (1992). Do Students' style preferences differ by grade level, orientation toward college, and academic major. Research in Higher Education, 33, 395-414.

Filipczak, B. (1995, March). Different strokes: Learning in the classroom. Training, 32, 43-48.

Karp, M. (1996). Theoretical aviation training for future airline pilots. Doctoral Dissertation, Walden University, Minneapolis, MN. UMI 9713644.

Karp, M, Condit, D., Nullmeyer, R. (1999). F-16 Cockpit/Crew Resource Management. (AL/HE-AZ-TR-1999-0253). Mesa, AZ: Air Force Research Laboratory.

Karp, M.R., Turney, M.A., \& McCurry, W.K. (1999). "Learning Style Theory and Aviation Education." Proceedings of Tenth International Symposium on Aviation Psychology, May 3-6, 1999, Columbus, OH.

Karp, M.R., McCurry, W.K., \& Harms, D. (2000). "Aviation Education and training for future regional airline pilots: An integrated process. Proceedings of the Regional Air Transportation Training Convention \& Tradeshow, February 8-9 2000, Daytona Beach, FL.

Knowles, M. (1980). The modern practice of adult education: From pedagogy to andragogy $\left(2^{\text {nd }} E d\right)$. New York: Cambridge Books.

Kozma, R. \& Johnston, J. (1991, January). The technological revolution comes to the classroom. Change, 16-18.

Matthew, R., Cooper, J., Davidson, N., \& Hawkes, P. (1995, July/August). Building bridges between cooperative and collaborative learning. Change, 27, 35-40.

Tannen, D. (1990). You just don't understand: women and men in conversation. New York: Ballentine Books.

Turney, M. (1995). Women's learning and leadership styles: Impact on CRM. Proceedings of the 21st Conference of the European Association for Aviation Psychology, Volume 1, Applications of Psychology to the Aviation System. Brookfield, Vermont: Ashgate Publishing Company.

United States Department of Transportation Federal Advisory Committee (1993, August). Pilots and aviation maintenance technicians for the twenty-first century: Assessment of availability and quality. Washington D.C.: U.S. Government Printing Office.

Zemke, R. \& Zemke, S (1995, June). Adult learning: What do we know for sure? Training, 32, 31-40.

Zemke, R. \& Zemke, S (2000). Proceedings of the Regional Air Transportation Training Convention and Tradeshow (RATS 2000), February 2000, at Daytona Beach Florida. Farnborough, UK: Civil Aviation Training (CAT) Magazine, Halldale Publishing. 